DOI: http://doi.org/10.21698/simi.2018.fp29

\title{
LOW HEATING VALUE PREDICTION FROM PROXIMATE ANALYSIS FOR SEWAGE SLUDGE SAMPLES
}

Agnes Serbanescu, Mona Barbu, Ileana Nicolescu, Georgeta Madalina Arama

National Research and Development Institute for Industrial Ecology - ECOIND, 71-73

Drumul Podu Dambovitei, district 6, 060652, Bucharest, agnes.serbanescu@incdecoind.ro, Romania

\begin{abstract}
As global renewable energy demand grows, sludge from urban waste water treatment plants could be one of the available renewable energy resources. Thermal treatment of sludge is becoming more and more attractive due to the destruction of dangerous constituents and the reduction of their volume.

The article presents a correlation equation based on the volatile matter content, which allows calculating the low heating value of sludge samples from a city wastewater treatment plant. The equation was developed by evaluating the characteristics of more than 40 sludge samples analysed in the laboratory. Validation of the equation revealed that the heating value deviation from the experimental one was below $3.5 \%$.

The estimation of the low heating value of sludge samples based on the determination of volatile matter content is important where the experimental determination of the low heating value involves time and the use of high-tech laboratory equipment.
\end{abstract}

Keywords: correlation equation, low heating value, sewage sludge, volatile matter

\section{Introduction}

As a result of the increase of the population connection rate to the sewage system and the modernization of the wastewater treatment plants, the statistical data show a $134 \%$ increase in the amount of sludge generated in 2014 compared to 2010 (192,000 $t$ in 2014) (PNGD 2017).

According to the National Institute of Statistics data, from the total amount of sludge treated in 2014, about 5\% were used in agriculture and about $75 \%$ were stored on their own platforms.

The use of sewage sludge as a fertilizer for agricultural lands can cause health risks by infesting the soil and groundwater with heavy metals, pathogens and viruses. These issues have generated a particular interest in other disposal alternatives, one of which is the combustion of sludge.

Waste energy recovery in the EU comes to support the achievement of the objectives of the Circular Economy Action Plan and is firmly guided by the EU hierarchy of waste (EC 2017).

Section Pollution Assessment \& Management Systems 242 


\section{INTERNATIONAL SYMPOSIUM "THE ENVIRONMENT AND THE INDUSTRY", SIMI 2018, PROCEEDINGS BOOK}

On the other hand, the combustion of sewage sludge is becoming more attractive as a removal option, due to the destroying of hazardous constituents and considerable volume reduction.

The use of sewage sludge as a source of renewable energy is an ecologically and economically efficient option, both in the EU and in the Romanian sludge management strategy.

Thermal processes involve removing the organic part of the sludge, leaving only the ash component for final disposal Sewage sludge is a type of biomass fuel, its heating value is similar to lignite (Fytili et al 2008). The main purpose of the thermal treatment of sewage sludge is to use the stored energy in the sludge and to minimize the impact on the environment at the same time, in order to meet the stricter standards.

The article presents a correlation equation for calculating the low heating value of the sludge resulting from a municipal wastewater treatment plant based on the volatile matter content.

Heating value is an important characteristic of sludge used in combustion plants. The higher heating value is determined experimentally by the complete burning of a known amount of sludge in the calorimetric bomb. The heat released by the combustion is transmitted to the calorimetric system comprising a known quantity of water which temperature is recorded.

The characteristic of the interest in combustion plants is the low heating value. The low heating value represents the number of heat units emitted by the complete combustion of a unit fuel mass under standard conditions, in which the water vapours formed during the combustion remains in the gaseous form, and consequently does not give up its latent heat of vaporization.

The low heating value may be calculated by subtracting the latent heat of water evaporation from the high heating value.

The experimental determination of the high heating value, and the calculation of the low heating value for a material, requires the use of performance laboratory equipment (calorimetric bomb, elemental analyser).

Another method for evaluate the heating value is the use of estimation equations assuming that the heating value of a hydrocarbon is given by the heat of combustion of carbon and hydrogen.

There are several types of equations for estimating heating value, such as those based on elemental composition. Dulong's formula is one of the famous equations that use elemental analysis results. This equation is often used to estimate the heating value of coals (anthracite, bituminous coal) with $1.5 \%$ error, compared to the values obtained experimentally.

Values calculated using the Dulong formula show deviations from the value determined experimentally for lignite and subbituminous coal due to their high oxygen content (Hosokai et al 2016). 


\section{INTERNATIONAL SYMPOSIUM "THE ENVIRONMENT AND THE INDUSTRY", SIMI 2018, PROCEEDINGS BOOK}

\section{Materials and Methods}

Laboratory experiments were performed on a number of approximately 40 mechanically dehydrated sludge samples from a municipal waste water treatment plant for a period of approx. 4 years.

The sludge samples were fully characterized using standardized methods. For characterization, the sludge samples were prepared in the laboratory by air drying at ambient temperature and milled using the Retsch Vibratory Disc Mill RS 200 in order to obtain a laboratory sample with a grain size less than $200 \mu \mathrm{m}$ (Serbanescu et al 2017, Kim et al 2017) .

Determination of moisture content and volatile matter $\left(550^{\circ} \mathrm{C}\right)$ was performed by gravimetric methods (ASRO 2002, 2007).

The higher heating value was determined by calorimetric method (ASRO 2009) using PARR 6200 calorimetric bomb. The low heating value was calculated (ASRO 2009) using the high heating value and the hydrogen content.

The elemental analysis, namely the determination of the carbon, nitrogen and hydrogen content, was performed by a chromatographic method using the Thermo Scientific FlashEA 1112 Elemental Analyzer (ASRO 2011). The FlashEA 1112 Elemental Analyzer is based on the well-known Flash Dynamic Combustion method, which produces complete combustion of the sample within a high temperature reactor, followed by an accurate and precise determination of the elemental gases produced (N2, CO2, H2O and SO2), using a TCD thermal conductivity detector. The sample combustion temperature was $950^{\circ} \mathrm{C}$.

The sulfur content was determined by gravimetric method using the washing waters from the calorimetric bomb (ASRO 2017).

\section{Results and Discussion}

In the laboratory research it was considered that the heating value of a sewage sludge would depend on the organic substance content and the technology used for waste water treatment and for residual sludge elimination.

Using the results obtained in the laboratory (Table 1), a correlation equation between the low heating value and the content of volatile matter is established, expressed on dry basis, for sludge samples from a municipal waste water treatment plant. The coefficients of the interpolation formula were established by the least squares method after the elimination of extreme values by mathematical statistical methods.

Figure 1 shows the interdependence between the low heating value and the content of volatile matter, in dry basis for the analysed sludge samples. The linear regression equation expressing the dependence of the two variables is: $y=37,895 x+605,2$ 


\section{INTERNATIONAL SYMPOSIUM "THE ENVIRONMENT AND THE INDUSTRY", SIMI 2018, PROCEEDINGS BOOK}

Table 1 Main physical-chemical characteristics of analysed sludge samples

\begin{tabular}{c|c|c|c|c|c|c|c}
\hline Sample & $\begin{array}{c}\text { Moisture } \\
{[\%]}\end{array}$ & $\begin{array}{c}\text { Volatile } \\
\text { matter, } \\
\text { [\% d.b.] }\end{array}$ & $\begin{array}{c}\text { LHV } \\
\text { [kcal/ } \\
\text { kg d.b.] }\end{array}$ & $\begin{array}{c}\text { C, } \\
{[\% \text { d.b.] }}\end{array}$ & $\begin{array}{c}\text { H, } \\
{[\% \text { d.b.] }}\end{array}$ & $\begin{array}{c}\text { N, } \\
{[\% \text { d.b.] }}\end{array}$ & $\begin{array}{c}\text { S, } \\
{[\% \text { d.b.] }}\end{array}$ \\
\hline 1 & 61,2 & 29.41 & 1700 & 16.79 & 3.10 & 2.45 & 0.64 \\
2 & 63,7 & 37.00 & 2159 & 20.70 & 3.62 & 2.98 & 0.63 \\
3 & 66,3 & 40.31 & 2194 & 21.23 & 3.06 & 3.44 & 1.01 \\
4 & 64,6 & 42.37 & 2098 & 20.36 & 3.35 & 3.06 & 0.70 \\
5 & 67,8 & 43.79 & 2326 & 24.79 & 3.52 & 3.34 & 0.84 \\
6 & 64,8 & 44.02 & 2253 & 23.94 & 2.92 & 3.98 & 0.63 \\
7 & 68,6 & 44.23 & 2416 & 24.49 & 3.05 & 3.54 & 0.78 \\
8 & 57,5 & 44.42 & 2221 & 21.68 & 3.50 & 3.07 & 0.42 \\
9 & 64,5 & 44.77 & 2266 & 24.96 & 3.52 & 3.52 & 0.80 \\
10 & 70,1 & 44.82 & 2145 & 24.67 & 1.88 & 4.35 & 1.11 \\
11 & 68,3 & 46.07 & 2322 & 25.31 & 3.24 & 3.93 & 0.79 \\
12 & 70,4 & 46.75 & 2401 & 25.22 & 2.88 & 3.28 & 1.18 \\
13 & 66,7 & 46.97 & 2236 & 21.84 & 4.01 & 3.69 & 0.66 \\
14 & 67,2 & 47.25 & 2387 & 26.39 & 3.44 & 3.55 & 0.65 \\
15 & 66,5 & 48.78 & 2291 & 23.71 & 3.26 & 3.25 & 1.10 \\
16 & 69,8 & 50.35 & 2666 & 27.21 & 3.41 & 3.94 & 0.96 \\
17 & 73,4 & 51.29 & 2530 & 26.51 & 3.00 & 4.51 & 1.16 \\
18 & 61,8 & 51.59 & 2675 & 27.59 & 3.44 & 3.81 & 0.72 \\
19 & 71,6 & 52.07 & 2630 & 25.99 & 4.11 & 4.40 & 0.75 \\
20 & 71,0 & 53.79 & 2709 & 27.10 & 4.09 & 4.58 & 0.81 \\
21 & 72,1 & 54.68 & 2775 & 27.21 & 4.30 & 5.30 & 0.79 \\
22 & 71,2 & 54.82 & 2686 & 26.68 & 4.12 & 4.43 & 0.83 \\
23 & 68,5 & 54.98 & 2581 & 25.60 & 3.97 & 3.61 & 0.84 \\
24 & 69,0 & 59.57 & 2835 & 28.90 & 4.73 & 3.71 & 0.85 \\
\hline
\end{tabular}

where:

d.b.-dry basis

LHV-low heating value

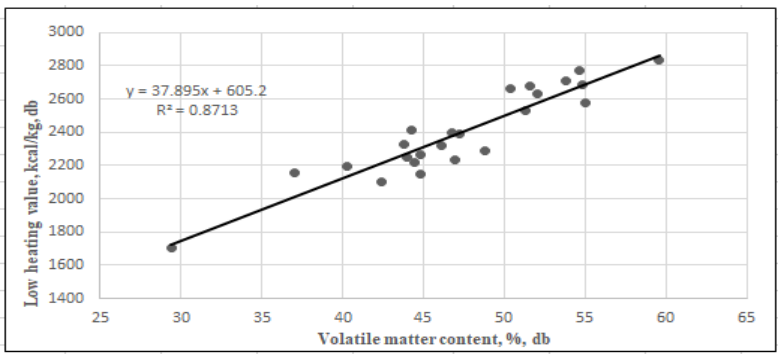

Figure 1. Interdependence between low heating value and volatile matter content of the analysed sludge samples 


\section{INTERNATIONAL SYMPOSIUM "THE ENVIRONMENT AND THE INDUSTRY", SIMI 2018, PROCEEDINGS BOOK}

For two Gaussian distributed data series, the most synthetic correlation indicator is the Pearson correlation coefficient $r$. The correlation coefficient is a quantitative value describing the relationship between two or more variables, representing the relationship between the covariance of the series and the product of their standard deviations, and shows values between -1 and 1 . The sign of the correlation coefficient indicates the direction of the association (inversely proportional to the sign - and directly proportional to the + sign) of the investigated variables ("Iuliu Hatieganu" University of Medicine and Pharmacy Cluj-Napoca, 2017).

The value for the correlation coefficient $r$ for the curve presented is 0.933 . According to Colton's empirical rules, a correlation coefficient greater than 0.75 (or less than -0.75) indicates a very good association or correlation of the variables.

The coefficient of determination $\mathrm{R}^{2}$ is the square of the correlation coefficient $\mathrm{r}$.

The value of the determination coefficient expresses an intensity of the linear relation between the two variables (low heating value and volatile matter content) or answers the question: how much of the variation of $\mathrm{Y}$ can be explained by the linear relationship with $\mathrm{X}$.

The value of the calculated coefficient for the presented curve is 0.8713 , suggesting a very good performance.

To determine whether the correlation coefficient is significant, so the two parameters (low heating value and volatile matter content) are correlated, the parameter t, considering 22 degrees of freedom was calculated. The value obtained by calculating parameter $\mathrm{t}$ is 12,2 . According to Student distribution, the value for $\mathrm{t}$ of 12,2 is converted to a probability error value: $p$, this being $<0,001$ leading to a relatively significant statistic between parameters (University of Medicine and Pharmacy-Craiova, 2018).

To validate the correlation equation between low heating value and volatile matter content, sludge samples from the same municipal wastewater treatment plant other than those used to establish the equation, were analysed. Table 2 shows the results obtained, which demonstrates that the use of the proposed equation represents a fast and relatively simple way to obtain a good estimation of the low heating value knowing the value of the volatile matter content. The differences between the calculated low heating values and those obtained by experimental determinations are below $3.5 \%$.

Figure 2 shows the applicability of the proposed equation for determining the low heating value for several sludge samples. The continuous line represents the equation describing the dependence between the low heating value and the volatile matter content.

The predicted low heating value for sludge samples, compared to those determined experimentally (Figure 3), indicates a good accuracy of the results. 
Table 2. Characteristics used for the correlation equation validation

\begin{tabular}{cccccc}
\hline Sample & $\begin{array}{c}\text { Volatile } \\
\text { matter, } \\
\text { (\% d.b.) }\end{array}$ & $\begin{array}{c}\text { LHV } \\
\text { (kcal/kg, d.b.) }\end{array}$ & $\begin{array}{c}\text { LHV } \\
\text { (kcal/kg, d.b.) }\end{array}$ & $\begin{array}{c}\text { Difference } \\
\text { (kcal/kg, d.b.) }\end{array}$ & $\begin{array}{c}\text { Difference } \\
\text { (\%) }\end{array}$ \\
\hline 1 & 40.81 & 2137 & predicted & & -0.69 \\
2 & 40.87 & 2105 & 2152 & -15 & -2.33 \\
3 & 42.26 & 2140 & 2207 & -67 & -3.11 \\
4 & 41.41 & 2128 & 2174 & -46 & 2,16 \\
5 & 44.14 & 2298 & 2278 & 20 & 0,88 \\
6 & 53.04 & 2610 & 2615 & -5 & 0,19 \\
7 & 53.2 & 2662 & 2621 & 41 & 1,54 \\
8 & 54.29 & 2717 & 2663 & 54 & 1,99 \\
9 & 54.48 & 2651 & 2670 & -19 & 0,72 \\
10 & 55.28 & 2643 & 2700 & -57 & 2,16 \\
11 & 57.56 & 2823 & 2786 & 37 & 1,31 \\
12 & 53.48 & 2677 & 2632 & 45 & 1.69 \\
\hline
\end{tabular}

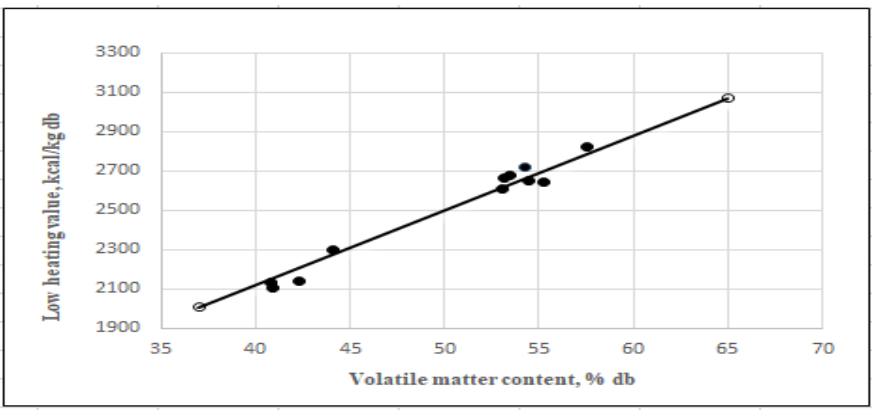

Figure 2. Application of the equation for low heating value for sludge samples

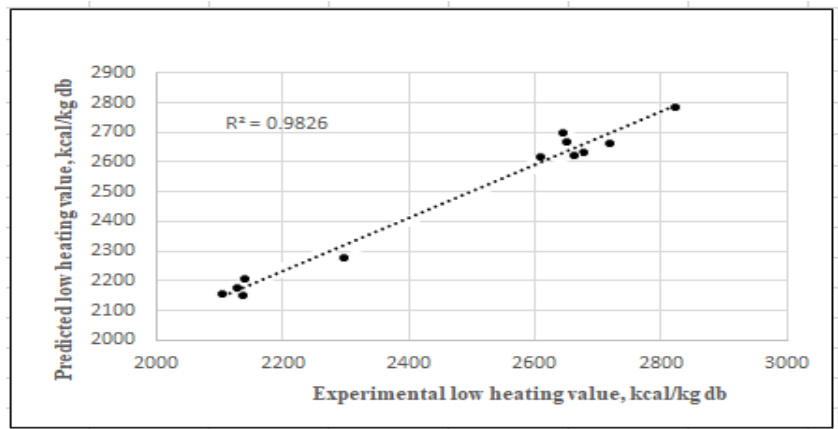

Figure 3. Experimental vs. predicted low heating value 


\section{INTERNATIONAL SYMPOSIUM "THE ENVIRONMENT AND THE INDUSTRY", SIMI 2018, PROCEEDINGS BOOK}

\section{Conclusions}

Laboratory experiments has highlighted the interdependence between the net heating values and volatile matter of sludge samples for a municipal waste water treatment plant. This interdependence is presented as a correlation equation wich allows to predict the low heating value of sludge samples using the volatile matter content, both at dry basis. The equation allows the calculation of an important indicator for combustion processes without using high-tech laboratory equipment.

The predicted low heating value for sludge samples, compared to those determined experimentally, indicates a good accuracy of the results.

\section{Acknowledgements}

This work was supported by Romanian Nucleu Programme, Project PN 18050401 „Innovative researches to support the achievement of national targets aligned with EU policy on waste management in the context of circular economy concept" being funded by Ministry of Research and Innovation.

\section{References}

ASRO 2002, SR EN 12880: 2002, Characterisation of sludge's-Determination of dry residue and water content.

ASRO 2007, SR EN 15169: 2007, Characterisation of waste-Determination of loss on ignition in waste, sludge and sediments.

ASRO 2009, SR EN 15170: 2009, Characterisation of sludge's-Determination of calorific value.

ASRO 2011, SR EN 15407:2011, Solid recovered fuels. Methods for the determination of carbon $(\mathrm{C})$, hydrogen $(\mathrm{H})$ and nitrogen $(\mathrm{N})$ content.

ASRO 2017, SR EN 14582:2017, Characterization of waste. Halogen and sulphur content. Oxygen combustion in closed systems and determination methods.

EC 2017 - EUROPEAN COMMISSION, The role of waste-to-energy in the circular economy, Brussels, 26.1.2017.

Fytili, D \& Zabaniotou, A 2008, 'Utilization of sewage sludge in EU application of old and new methods', Renewable and Sustainable Energy Reviews, vol. 12, no. 1, pp. 116-140.

Hosokai, S, Matsuoka, K, Kuramoto, K \& Suzuki, Y 2016, 'Modification of Dulong s formula to estimate heating value of gas, liquid and solid fuels', Fuel Processing Technology, vol.152, pp. 399-405.

Kim, L, Muresan, AM, Cuciureanu, A, Guta, D, Arama, M, Cristea, NI, \& Dediu, V 2017, 'Experimental models of characterization and analysis of industrial waste', 20 $0^{\text {th }}$ International Symposium “The Environment and The Industry”, SIMI 2017, National Research and Development Institute for Industrial Ecology ECOIND, Bucharest, pp. 142-150.

PNGD 2017- National Waste Management Plan, Romanian Official Monitor no. 11 bis from 5th January, 2018. In Romanian. 
Serbanescu, A, Barbu, M, Nicolescu \& Bucur, I 2017, 'Interdependence between total organic carbon content and heating value of sewage sludge samples', $20^{\text {th }}$ International Symposium “The Environment and The Industry”, SIMI 2017, National Research and Development Institute for Industrial Ecology ECOIND, Bucharest, pp. 272-278.

University of Medicine and Pharmacy Iuliu Hatieganu Cluj-Napoca 2017, Correlations and regressions, Available from: https://www.info.umfcluj.ro/ro/did-ro/biostat ro/mg1ro-ro/item/1050-curs-12corelatii-si-regresii. [10 July 2017]. In Romanian.

University of Medicine and Pharmacy from Craiova 2018, Course 5, Statistical Correlation, Available from: https://www.umfcv.ro/medicina-dentara, studenti- disciplina-informatica-medicala.shtml. [04 July 2018]. In Romanian. 